\title{
Avaliação da Susceptibilidade à Fragilização Induzida por Hidrogênio na Soldagem de um Aço Microligado para Blindagens por meio de um Ensaio de Implante com Geometria Modificada
}

\author{
(Evaluation of Susceptibility of Hydrogen Induced Cracking in Microalloyed Armor Steel Welds using a Geometry Modified \\ Implant Test)
}

\author{
Jimy Unfried Silgado ${ }^{1}$, Edwar Torres Lopez ${ }^{1}$, Antonio Jose Ramirez ${ }^{1}$, Jorge Giraldo Barrada ${ }^{2}$ \\ ${ }^{1}$ Laboratório Nacional de Luz Síncrotron - LNLS, Campinas-SP Brasil. \\ ${ }^{2}$ Grupo de soldadura. Universidad Nacional de Colombia - Sede de Medellín, Colombia.
}

\begin{abstract}
Resumo
A susceptibilidade à fragilização induzida pelo Hidrogênio (FIH) foi avaliada em soldas de aço para blindagem temperado e revenido $(T \& R)$ de 4,5mm de espessura. As soldas foram desenvolvidas utilizando o processo SMAW com um baixo aporte de calor e consumível AWS E11018M de 2,4 mm. A susceptibilidade a FIH foi avaliada por médio de um ensaio de implante com geometria modificada em juntas soldadas com e sem aplicação de preaquecimento, utilizando consumíveis em condições de estocagem ideais e expostos à atmosfera. Encontrou-se que a condição de estocagem do consumível foi mais relevante que o preaquecimento na susceptibilidade ao FIH.
\end{abstract}

Palavras Chave: Blindagem balística, fragilização induzida pelo Hidrogênio (FIH), Ensaio do Implante.

Abstract: The Hydrogen Induced Cracking (HIC) susceptibility of 4,5mm thickness quenched and tempered $(Q \& T)$ armor plate steel welding joints was evaluated. The joints were obtained using low heat input and SMAW process with 2,4 mm AWS E11018M electrode. The HIC susceptibility was evaluated using a geometry modified implant test for thin plates. The joints studied were produced with and without preheating and using welding electrodes with and without exposure to atmospheric conditions. The HIC resistance was severely impaired by improperly storage while preheating conditions did not preclude HIC.

Key words: Armor plates, Hydrogen Induced Cracking, Implant Test.

\section{Introdução}

Os aços microligados utilizados em aplicações de blindagem são materiais que possuem dureza e resistência mecânica elevadas com o fim de suportar impactos de projétil a determinadas velocidades [1]. Esta capacidade é resultado da combinação entre uma refinada composição química e o controle do processo de laminação e tratamento térmico [2]. Um tipo de material que possui estas características são os aços microligados para blindagens temperados e revenidos (T\&R). Estes materiais derivam seu desempenho balístico da sua microestrutura composta por Martensita revenida a baixa temperatura, o qual garante uma combinação de dureza e tenacidade elevadas, necessárias neste tipo de aplicações [3].

Os processos de soldagem por fusão têm-se mostrado como o método mais efetivo na união deste tipo de materiais [4]. No entanto, a alteração da microestrutura adjacente à região de soldagem modifica as propriedades mecânicas necessárias para o ótimo desempenho como material de blindagem. Alguns estudos realizados em aços de alta resistência e de baixa liga

(Recebido em 20/05/2007; Texto Final em 28/07/2009).
(ARBL) confirmam que, independentemente do processo de soldagem utilizado, apresenta-se uma variação da dureza na região adjacente ao metal fundido, cuja extensão é função dos parâmetros de soldagem. Neste tipo de junções tem sido observadas regiões de martensita não revenida de alta dureza (>500 HV) com uma extensão entre 2 e 3 mm [2-5].

Uma das principais dificuldades na soldagem destes materiais é a elevada susceptibilidade à fragilização da martensita pelo hidrogênio, geralmente associada à contaminação por umidade nos consumíveis de soldagem ou à decomposição de sustâncias presentes nos componentes soldados. Este fenômeno gera a nucleação e crescimento de trincas no local do cordão de solda ou na zona afetada termicamente (ZAT), efeito conhecido como fragilização induzida pelo hidrogênio (FIH) [6-8]. Para evitar a ocorrência do FIH é preciso empregar condições de soldagem que permitam a redução dos níveis de hidrogênio no metal de solda e evitar que $\mathrm{o}_{2}$ migre para a ZAT ou inibir a formação da martensita não revenida nesta mesma região.

Entre os diversos ensaios para avaliar a susceptibilidade ao FIH sob condições de fabricação neste tipo de aço, destacamse o teste de Severidade Térmica Controlada (Controlled Thermal Severity - CTS), o teste da placa H ( $H$ - Test $)$ e o teste de implante (Implant test). O ensaio CTS [9] consiste num dispositivo fabricado a partir de duas chapas, uma retangular e 
outra quadrada, cada uma com um furo central unidas com um parafuso e restringidas mediante cordões de solda, segundo a configuração da figura 1 . O dispositivo é montado num suporte a $45^{\circ}$ (ver figura 1 b), para permitir uma fácil aplicação do cordão de solda de teste. Logo após da aplicação da solda, o conjunto é resfriado rapidamente em água sob condições controladas. Finalmente, as seções soldadas são cortadas como mostrado na figura 1(c), preparadas metalograficamente e examinadas. Neste tipo de ensaio as trincas podem se desenvolver tanto na ZAT quanto na zona fundida (ZF). O CTS possui como vantagens utilizar cordões de solda curtos, possibilitando a reprodução
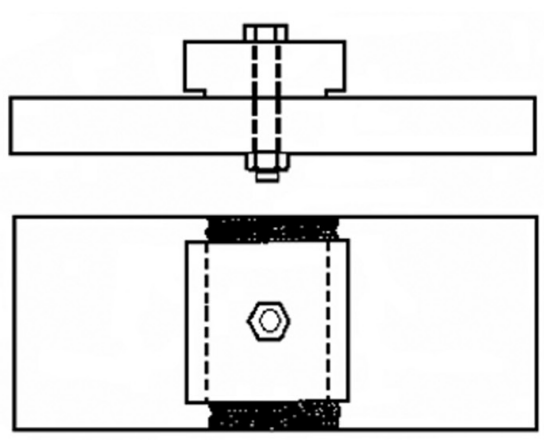

(a)

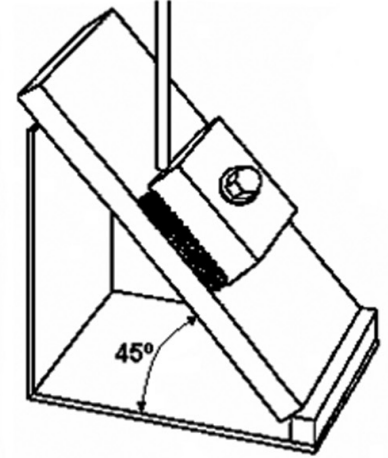

(b) de diversos parâmetros de soldagem. Entre as desvantagens do teste destacam-se a necessidade de usar vários processos de usinagem, a baixa reprodutibilidade dos resultados e um único nível de restrição mecânica o qual pode ser diferente das condições de soldagem em campo dependendo da espessura de chapa. Devido à baixa restrição mecânica imposta no ensaio CTS, é freqüiente a não formação de trincas mesmo sob condições altamente favoráveis para o desenvolvimento do FIH. Este fato foi verificado por outros autores, para casos em que o valor da restrição durante o teste não atingiu o esforço crítico de propagação de trincas [13].

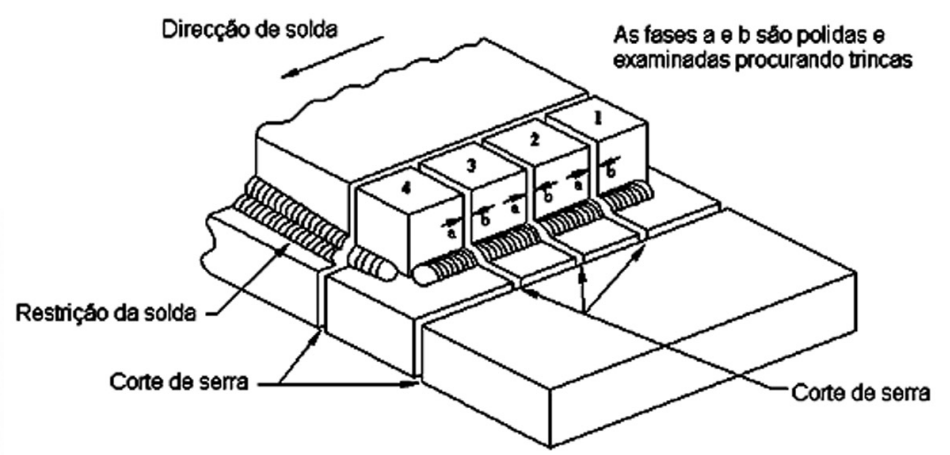

(c)

Figura 1. (a) Ilustração esquemática do ensaio CTS, (b) sua montagem e (c) localização de cortes para inspeção.

No ensaio da placa $\mathrm{H}[10]$ é fabricado um corpo de prova a partir de quatro chapas unidas por cordões de solda em forma de $\mathrm{H}$, cuja seqüência de soldagem é feita de tal modo que o último cordão aplicado é o horizontal, o qual fica altamente restrito como apresentado na figura 2. A principal vantagem deste teste é permitir a reprodução de condições mais próximas às de fabricação, especialmente a elevada restrição mecânica imposta pela configuração e comprimento dos cordões aplicados, os quais podem atingir um regime térmico estacionário. Entre as desvantagens do teste estão o alto custo da produção dos corpos de prova, a impossibilidade de controlar estritamente o regime de aquecimento dificultando a identificação do mecanismo de desenvolvimento de trincas envolvido em uma eventual falha. $\mathrm{O}$ alto custo dos ensaios de placa $\mathrm{H}$ e as dificuldades associadas à identificação das causas da nucleação e propagação de trincas [14], desfavorecem o uso deste ensaio.

O ensaio de implante é freqüentemente aplicado na avaliação do FIH na ZAT de aços ARBL [9-12]. O corpo de prova do teste é formado por uma chapa de $200 \mathrm{~mm} \times 150 \mathrm{~mm}$ com a espessura de avaliação, como mostrado na figura 3(a). Nesta chapa é inserido um extremo de uma barra, usualmente de seção circular, roscada ou entalhada. A extremidade superior da barra fica paralela à face sobre a qual se aplica um cordão de solda reto no sentido longitudinal da chapa. O cordão aplicado deve ter uma largura superior ao diâmetro da barra cobrindo totalmente a junção, como ilustrado na figura 3(b). No caso que seja utilizada uma barra entalhada, o entalhe deve se localizar na região susceptível ao FIH. Imediatamente após a soldagem, o corpo de prova é submetido a tração estática pela aplicação

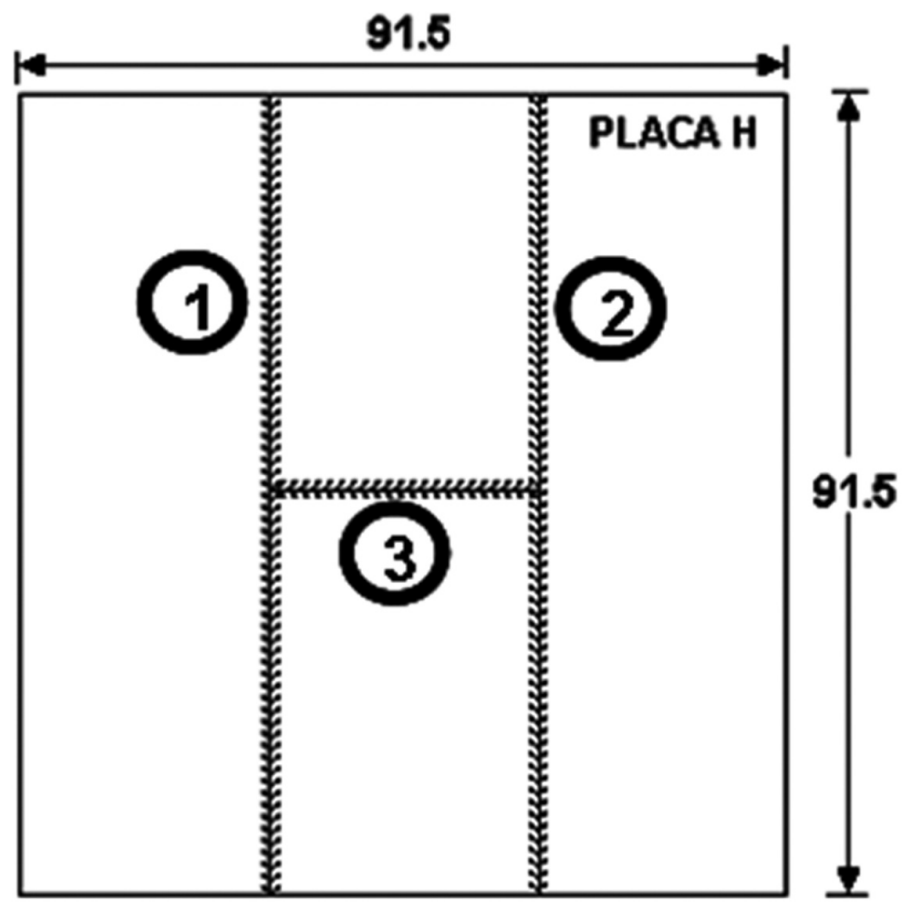

Figura 2. Disposição da montagem do ensaio da placa $\mathrm{H}$, com medidas em mm. Os números mostram a seqüência de soldagem no teste. 
de uma carga na extremidade livre da barra, condição que reproduz a restrição mecânica na junção soldada. O teste tem como propósito estabelecer relações entre o tempo, o esforço de ruptura (obtido sob aplicação da carga) e os parâmetros utilizados $[9,11]$. Neste caso, se considera a rosca e o entalhe como local de nucleação das trincas. Entre as desvantagens deste teste destacam-se a necessidade de usinagem mais precisa em comparação aos ensaios anteriormente descritos, o uso de equipamentos adicionais requeridos para aplicação da tensão e controle de temperatura e, finalmente, a falta de informação técnica em relação a sua aplicação em chapas com espessuras inferiores a $6 \mathrm{~mm}$ [9-10]. A principal vantagem do ensaio de implante está na possibilidade de escolha do valor da carga aplicada, possibilitando um melhor controle da restrição mecânica, além do menor tamanho dos corpos de prova. A pesar do alto custo do ensaio de implante, este agrupa importantes vantagens dos ensaios CTS e placa $\mathrm{H}$
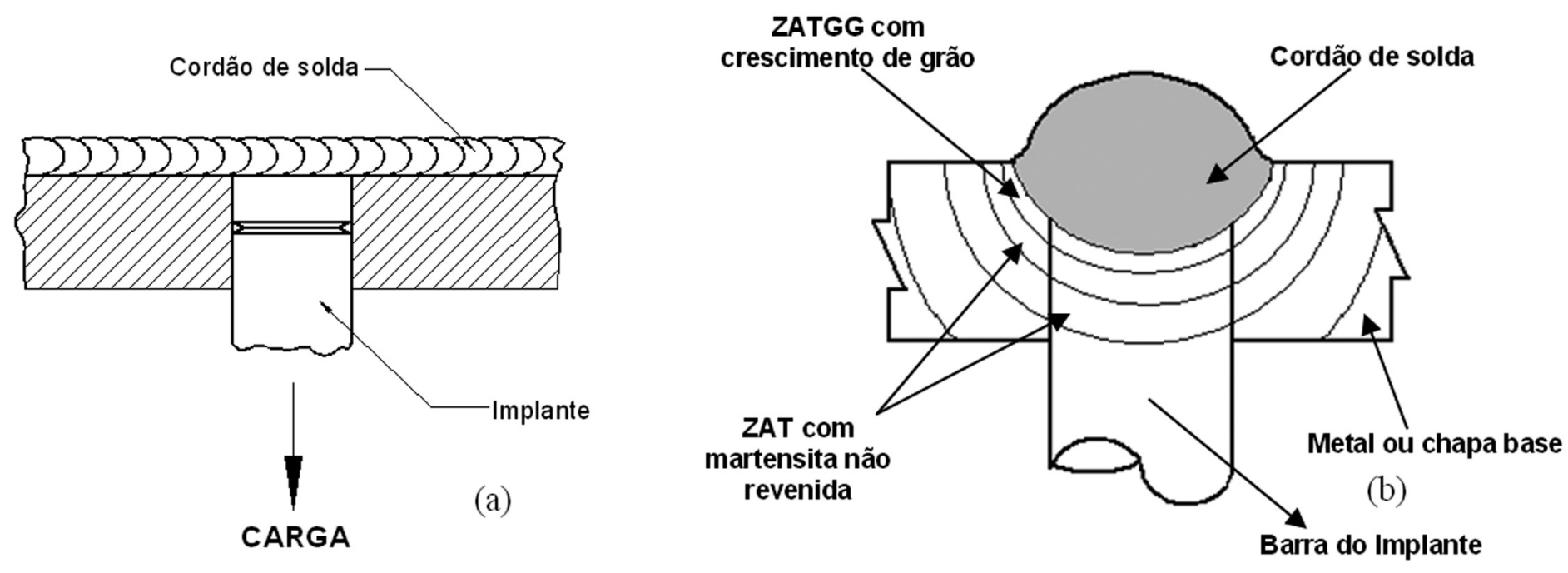

Figura 3. Representação esquemática do ensaio de implante convencional (a) vista lateral (b) corte transversal.

O objetivo deste trabalho é avaliar a susceptibilidade à fragilização induzida pelo Hidrogênio (FIH), em chapas finas de um aço para blindagem sob as seguintes condições: com e sem aplicação de preaquecimento; e com os consumíveis sob condições tanto de estocagem ideais quanto expostos à atmosfera. Tal avaliação é feita utilizando planejamento experimental estatístico (DOE) e um ensaio de implante com geometria modificada.

\section{Materiais e Método Experimental}

Os corpos de prova e as barras entalhadas do teste de implante foram produzidos a partir de uma chapa de $4,5 \mathrm{~mm}$ de espessura do aço T\&R, cuja composição química e propriedades mecânicas mais relevantes são apresentadas na tabela 1. A figura 4 mostra a geometria, dimensões e características dos corpos de prova. Foi utilizado o processo de soldagem a arco elétrico com eletrodo revestido (SMAW - Shielded Metal Arc Welding), com baixo aporte de calor (soldagem plana, $80 \mathrm{~A}, 26 \mathrm{~V}, 3,2-3,8 \mathrm{~m} \cdot \mathrm{s}^{-1}$, $\sim 550 \mathrm{~J} . \mathrm{mm}^{-1}$ ). O material de adição utilizado foi o eletrodo ferrítico de alta resistência com especificação AWS E11018M e diâmetro de 2,4 mm, cuja composição sem diluição (as-welded) é exibida na tabela 2 . O entalhe da barra foi localizado entre 2 e 2,5 mm da superfície superior da chapa, dentro da região de martensita não revenida da ZAT, localização que foi escolhida de acordo com resultados previamente obtidos utilizando os mesmos materiais e processos [4, 14-15].

As soldas foram feitas sobre superfícies limpas, livres de poeira, gordura e óxidos com um equipamento de soldagem Miller XTM300A. A aplicação da carga de tração foi feita numa máquina hidráulica de ensaios de tração universal VEB Leipzig com capacidade de $1000 \mathrm{kgf}$. e resolução de $\pm 5 \mathrm{kgf}$. Os corpos de prova foram cortados mediante eletroerosão com auxilio de uma broca de tungstênio de 2,4 $\mathrm{mm}$ para realizar o encaixe central do implante.

O preaquecimento do conjunto foi realizado em um forno elétrico e o controle da temperatura foi realizado usando um termômetro infravermelho Fluke 125. O controle das variáveis elétricas do processo de soldagem foi realizado utilizando um amperímetro AC/DC Kyoritsu RMS 2009 de 2000 A e 1000/750 V. A observação metalográfica foi feita em um microscópio óptico Olympus PME3B acoplado a um sistema de analise de imagens LEICA GZ6 e em um microscópio eletrônico de varredura JEOL JSM $5910 L V$ operando no modo SEI com $25 \mathrm{kV}$ de tensão. A preparação metalográfica das amostras foi padrão e o polimento realizado com alumina de 1,0 e $0,3 \mu \mathrm{m}$. O ataque químico foi com Nital $4 \%$. 


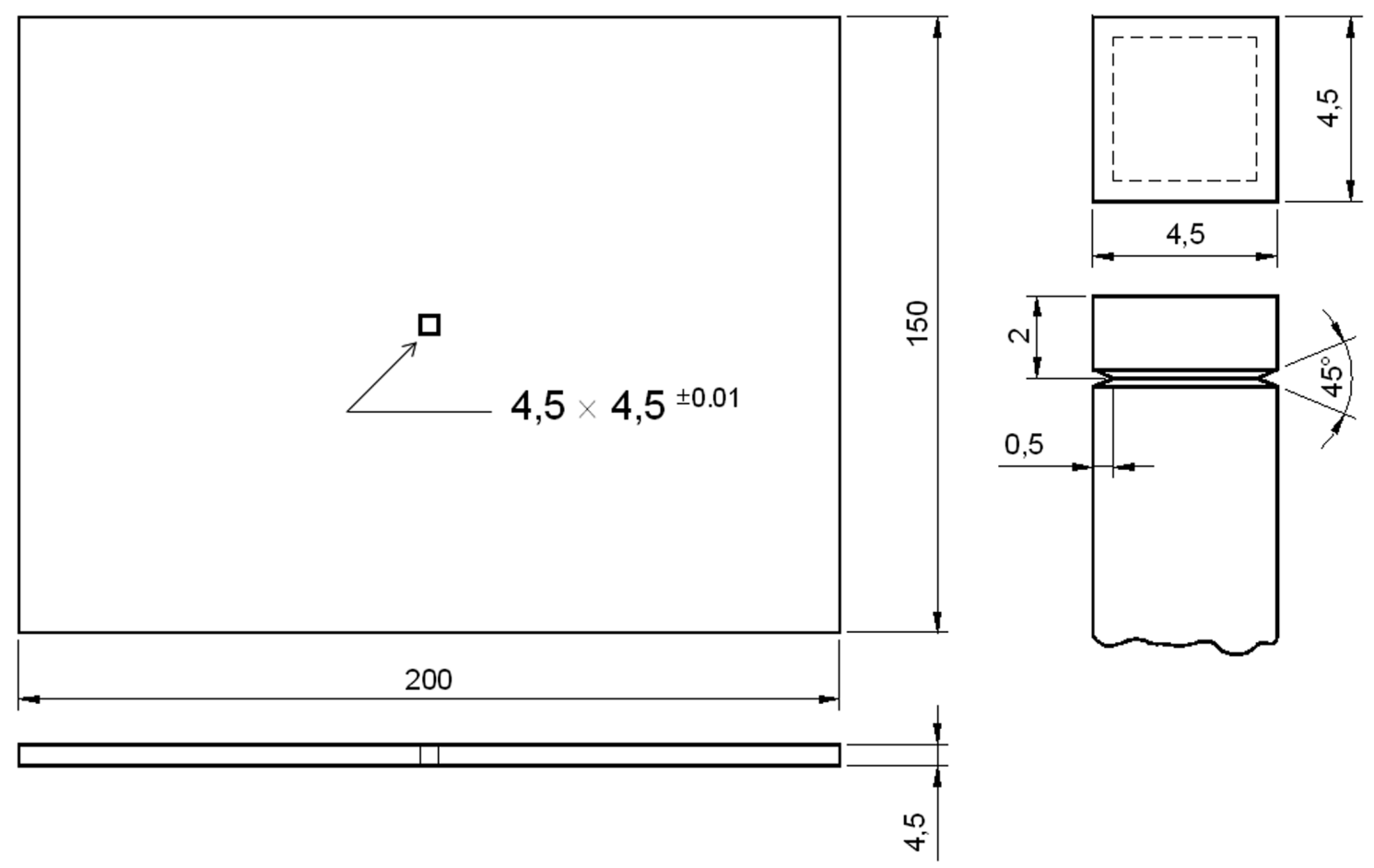

Figura 4. Ilustração esquemática da geometria e dimensões do corpo de prova para o ensaio de implante modificado. O implante tem um comprimento total de $100 \mathrm{~mm}$.

Tabela 1. Composição química e propriedades do aço temperado e revenido (a $\left.200^{\circ} \mathrm{C}\right)$

\begin{tabular}{|c|c|c|c|c|c|c|c|c|c|c|}
\hline C & $\mathbf{N i}$ & Mn & $\mathrm{Cr}$ & Mo & Si & V & $\mathbf{T i}$ & $\mathbf{C u}$ & Al & $\mathbf{S}$ \\
\hline 0,28 & 0,19 & 0,90 & 0,30 & 0,24 & 0,53 & 0,007 & 0,03 & 0,18 & 0,02 & 0,002 \\
\hline Dure & $\overline{\mathrm{BH}}$ & $; \mathrm{R}$ & & tra & $\begin{array}{l}=17 \\
\mathrm{a}-4\end{array}$ & & & & & $22 a$ \\
\hline
\end{tabular}

Tabela 2. Composição química do metal de adição AWS E11018M sem diluição.

\begin{tabular}{ccccccccc}
\hline $\mathbf{C}$ & $\mathbf{N i}$ & $\mathbf{M n}$ & $\mathbf{C r}$ & $\mathbf{M o}$ & $\mathbf{S i}$ & $\mathbf{V}$ & $\mathbf{S}$ & $\mathbf{F e}$ \\
\hline 0,05 & 2,23 & 1,64 & 0,36 & 0,37 & 0,46 & 0,02 & 0,01 & Bal. \\
\hline
\end{tabular}

Foi projetado um experimento para quantificar a susceptibilidade ao FIH a partir da medição do comprimento da trinca na região entalhada [15]. Para tal propósito, foi utilizado o modelo de análise de variância ANOVA para dois fatores o qual foi aplicado ao teste de implante modificado. Os fatores e seus respectivos níveis selecionados foram:

- Temperatura de preaquecimento (TP): sem preaquecimento (TP1) e com preaquecimento a $75^{\circ} \mathrm{C}$ (TP2) segundo recomendação da AWS [16].

- Nível de umidade relativa dos eletrodos $(\mathrm{NH})$, relacionada ao conteúdo de hidrogênio nos revestimentos dos mesmos devido à exposição às seguintes condições: (NH1), eletrodos secos em forno a $450{ }^{\circ} \mathrm{C}$ por 1 hora e armazenados em fornos portáteis a $150^{\circ} \mathrm{C}$ antes do uso (atingindo um valor de umidade $<0.4 \%$ em peso segundo recomendação do fabricante [14]), e (NH2) eletrodos expostos a temperaturas entre $25^{\circ} \mathrm{C}$ a $31^{\circ} \mathrm{C}$ e uma umidade relativa no ambiente entre 80 e $95 \%$ sem secagem posterior em forno com um tempo de exposição de $120 \mathrm{~h}$. Neste ultimo caso a umidade contida nos eletrodos não foi medida.

Com um desvio padrão da media de $\pm 0,8 \mathrm{~mm}$ com relação ao valor do comprimento da trinca total $(r)$, selecionado a partir de resultados de um teste circular (circular path test) juntamente com os valores anteriores, estimou-se que o número necessário de réplicas por cada tratamento aplicado era quatro [15]. Os valores da potência estatística e da significância utilizados foram de $1-\beta=0,08$ e $\alpha=0,05$ respectivamente. A carga de tensão estática aplicada foi de $400 \mathrm{kgf}$., equivalente ao valor do limite elástico do aço utilizado, valor que foi calculado levando em conta a geometria e o entalhado do implante [17]. A dificuldade de usinar o material devido à sua alta dureza condicionou a seleção do formato de seção prismática no implante (Figura 4). 

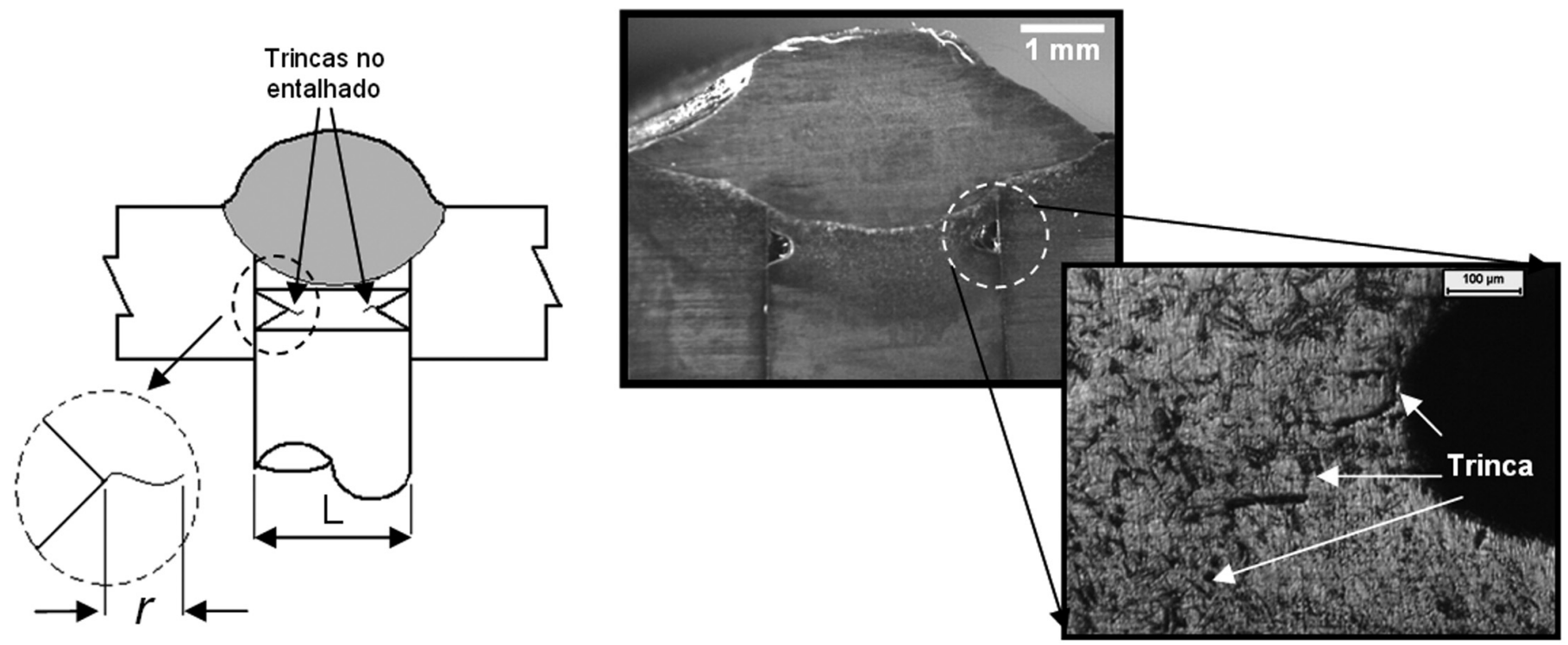

Figura 5. Seção transversal de exploração de trincas no corpo de prova testado no ensaio de implante.

Os corpos de prova foram soldados em uma sequência aleatória de acordo com as condições experimentais estabelecidas. Mediu-se o tempo de aplicação da carga de tensão até o conjunto falhar ou completar 3600 s como tempo máximo de teste [13]. Seções transversais de todas as amostras foram cortadas e preparadas metalograficamente como apresentado na figura 5. Foi verificado em todos os casos que o entalhe ficou dentro da região da ZAT próxima à linha de fusão. Foi realizada inspeção mediante microscopia óptica usando uma ampliação de 100X na procura de trincas. O comprimento das trincas foi medido com ajuda do analisador de imagens; a resolução foi de $\pm 1 \mu \mathrm{m}$ no aumento especificado. Algumas superfícies de fratura foram estudadas no MEV. O critério utilizado na avaliação do FIH baseou em um comprimento de trinca superior a 5\% do total da seção transversal do entalhe, expressado matematicamente como: $2 \mathrm{r} / \mathrm{L}>0,05$, sendo $r$ a soma do comprimento das trincas observadas nos cantos entalhados da junção e $L$ o comprimento da diagonal do implante [11].

\section{Resultados}

Na tabela 3 são apresentados os resultados do comprimento da trinca medidos para cada tratamento segundo o procedimento anteriormente descrito. Nas figuras 6(a) a 6(c) são apresentados graficamente os resultados nas diversas condições avaliadas, assim como um arranjo de imagens de todos os implantes testados.

Na tabela 4 são apresentados os resultados da análise de variância (ANOVA). Nela se apresenta toda a informação relevante sobre a validação do modelo estatístico utilizado. Nota-se que o valor observado de $F_{o}(11,81)$ é maior que o seu valor crítico $\left(F_{C}=3,49\right)$ e o valor $p$ é menor que o valor da significância proposta $\alpha=0,05$, indicando a existência de diferenças entre os tratamentos aplicados.

Tabela 3. Dados do comprimento da trinca para cada condição de tratamento imposta durante o ensaio.

\begin{tabular}{ccccc}
\hline \multirow{2}{*}{ Condições } & \multicolumn{4}{c}{ Replica ou blocos do ensaio / Comprimento medido da trinca [mm] } \\
\cline { 2 - 5 } & Primeira & Segunda & Terceira & Quarta \\
\hline NH1 - TP1 & Sem trincas & Sem trincas & Sem trincas & 0,43 \\
\hline NH1 - TP2 & 0,11 & 0,38 & Sem trincas & 0,49 \\
\hline NH2 - TP1 & 1,69 & 3,00 & 1,86 & 3,00 \\
\hline NH2 - TP2 & 1,41 & Sem trincas & 1,82 & Sem trincas \\
\hline
\end{tabular}

Tabela 4. Resultados da análise de variância utilizando o teste do implante modificado.

\begin{tabular}{c|c|c|c|c|c}
\hline Fonte de variação & $\begin{array}{c}\text { Graus de } \\
\text { liberdade }\end{array}$ & $\begin{array}{c}\text { Soma de } \\
\text { quadrados (SS) }\end{array}$ & $\begin{array}{c}\text { Valores quadrados } \\
\text { médios }\end{array}$ & $\mathbf{F}_{\mathbf{o}}$ & Valor $\boldsymbol{p}$ \\
\hline Entre grupos & 3 & 13,11 & 4,37 & 11,81 & 0,0072 \\
\hline Dentro dos grupos & 12 & 4,51 & 0,37 & & \\
\hline Total & 15 & 17,62 & \multicolumn{2}{|c|}{$\mathrm{F}_{\text {crítico }}=\mathrm{F}_{\mathrm{C}}=\mathrm{F}_{0.05,3,12}=3,49}$. \\
\hline
\end{tabular}



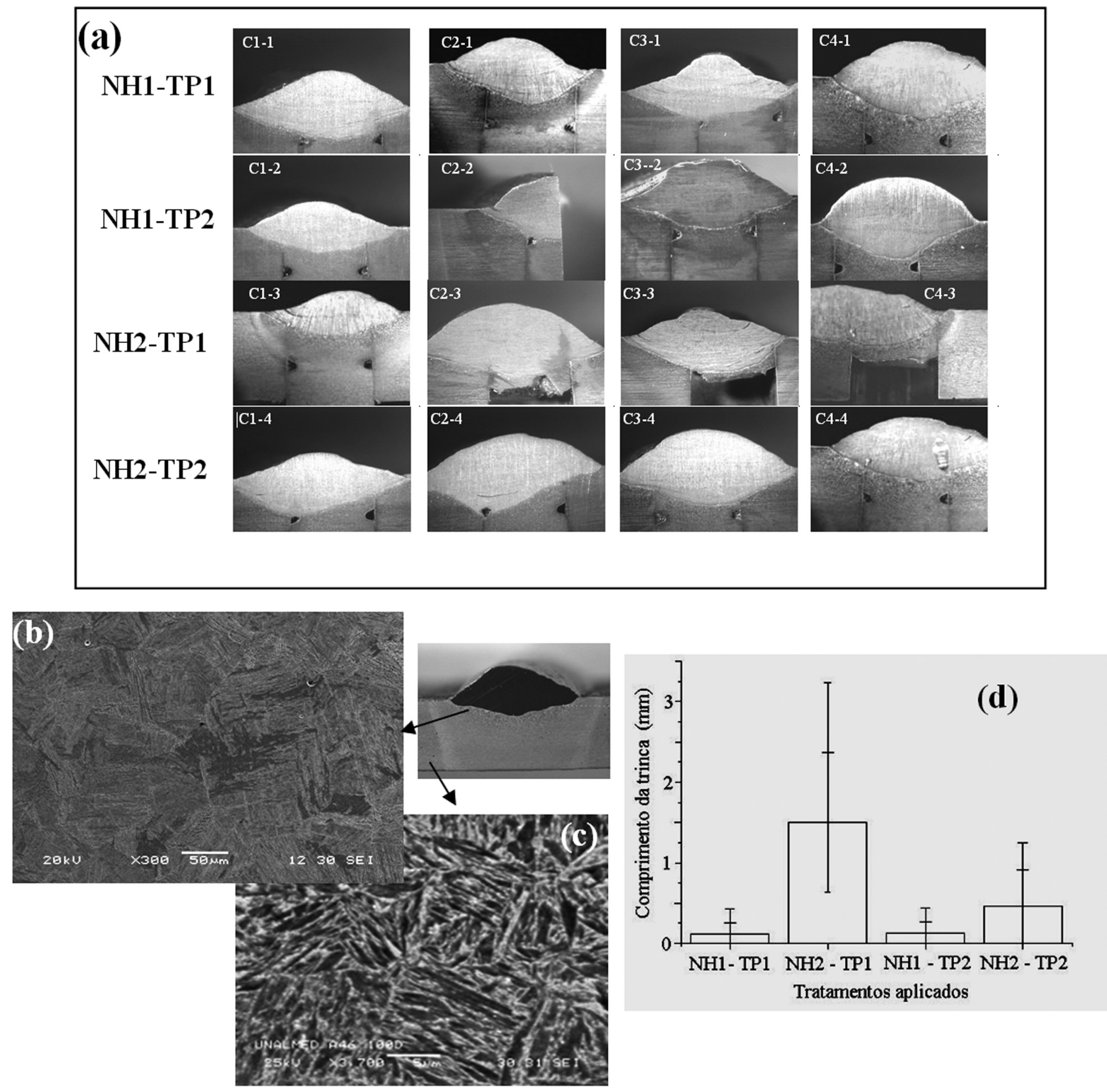

Figura 6. Imagens relacionadas com os ensaios de implante modificado: (a) Macrografías da seção transversal dos implantes testados. Os corpos de prova C2-2 e C3-3 foram cortados intencionalmente para observação (b) Imagem MEV no modo SE da região da ZAT com martensita não revenida e grão grosseiro; (c) Imagem MEV no modo SE do metal de base; (d) Diagrama de barras mostrando o comportamento do comprimento da trinca em função do tratamento aplicado.

Análises dos efeitos individuais dos fatores NH e TP, mostram que o efeito do nível de umidade relativa nos eletrodos é mais significativo que a aplicação de temperatura de preaquecimento; mais detalhes podem ser observados na referência [15].

\section{Discussão}

A insuficiência de dados que forneçam informação da susceptibilidade ao FIH neste tipo de materiais estratégicos sustenta a motivação deste trabalho. Apesar de terem sido feitas diversas avaliações no aço T\&R aqui estudado, utilizando o mesmo tipo de material de adição, pelos ensaios CTS e de placa $\mathrm{H}$ sob condições favoráveis para a ocorrência de FIH, os resultados não mostraram indícios de desenvolvimento de trincas [4,14-15]. Outras experiências feitas usando ensaio CTS em aços similares apresentaram resultados altamente dispersos com o mesmo tipo de consumível e sob condições similares [1314]. 
Segundo a tabela 4, os resultados indicam a ocorrência de FIH em soldas expostas a um maior nível de umidade e ausência de preaquecimento. A condição de umidade nos eletrodos resultou mais relevante que a aplicação da temperatura de preaquecimento para cada tratamento. $\mathrm{O}$ fato anterior coincide com resultados experimentais bem documentados [13]. Nesta experiência foi evidente que juntas altamente restritas do aço T\&R possuem baixa tolerância a níveis de hidrogênio na ZAT possibilitando a ocorrência da fragilização, fenômeno que não foi possível observar com os outros ensaios.

Do ponto de vista do modelo estatístico, o valor $p$ obtido (menor que ), valida a hipótese dos fatores terem efeito na susceptibilidade ao FIH. Apesar disto, os resultados obtidos no teste de implante modificado (tabela 3) apresentaram uma dispersão considerável. Estima-se que a alta dispersão dos resultados pode estar associada à mudança no formato do implante e à localização do entalhado em relação à penetração e ao formato do cordão de soldagem como mostrado na figura 6 . Em relação ao primeiro ponto, os autores sugerem a utilização de elementos finitos e elementos de contorno para avaliar os efeitos do entalhe em seções prismáticas sob tensão. No segundo caso, a realização de mais experiências com estrito controle de variáveis poderia ajudar a minimizar a dispersão. O acompanhamento das medidas de hidrogeno difusível seria indispensável neste último caso.

De forma similar aos outros tipos de aços carbono e de baixa liga, a zona afetada termicamente (ZAT) dos aços para blindagens T\&R é composta de sub-regiões com microestrutura e propriedades bem definidas, as quais são o resultado da historia térmica durante a soldagem [18]. Para estes aços, considerando que as regiões completamente austenitizadas da ZAT (tanto a de crescimento como a de refino de grão) tendem a se transformar em martensita no resfriamento durante a soldagem, uma divisão da ZAT frequentemente utilizada na literatura $[3,5,8,15]$ e adotada neste trabalho é a seguinte: (a) Região de austenitização total, a qual possui martensita não revenida e pequenas frações de bainita; nesta região co-existem duas sub-regiões que possuem alta dureza e fragilidade, diferenciadas pela forma da martensita e do tamanho do grão prévio da austenita, as quais são a sub-região de martensita de grão grosseiro (ZATGG) e a sub-região de martensita com grão fino (ZAT-GF); (b) Região de austenitização parcial, a qual contém frações de martensita revenida, ferrita poligonal e Bainita; com relação à região anterior a dureza diminui abaixo de valores críticos para resistência balística devido às transformações parciais dentro da zona intercritica do aço (ZAT-IC). (c) Região de revenido ou de transformações subcríticas a qual possui, dependendo da temperatura de pico atingida, diversos graus de revenimento da martensita (ZAT-SC) [3,5,14-15,17-18]. De acordo com a análise anterior, as regiões ZAT-GG e ZAT-GF podem apresentar alta susceptibilidade ao FIH neste tipo de materiais.

Em uma região soldada pode ocorrer FIH quando se apresenta a combinação de alta dureza, presença de uma microestrutura suscetível ao desenvolvimento de trincas, tal como a martensita, e enriquecimento de hidrogênio atômico proveniente do metal fundido com temperabilidade menor em relação ao metal de base utilizado [6]. A localização do entalhe com relação às regiões de soldagem se torna crítica na aplicação do ensaio proposto; no entanto a localização selecionada neste trabalho é razoável com as características da região onde é provável a ocorrência do FIH neste tipo de materiais [14-15, 17-18]. O entalhe dos implantes atua ao mesmo tempo como concentrador de esforços e como armadilha de hidrogênio gasoso, explicando a alta probabilidade de ocorrência das trincas nesta região [11].

Na figura 7 se apresentam imagens da superfície no inicio da fratura de uma das amostras (figura 5) soldada sob a condição NH2-TP1. Observa-se que a falha localizada na zona de austenitização total tem características de fratura intergranular, uma característica típica do tipo de falhas por FIH. Alguns locais da superfície de fratura possuem características de quase-clivagem, tipicamente observados em aços temperados e revenidos que falham fragilmente.
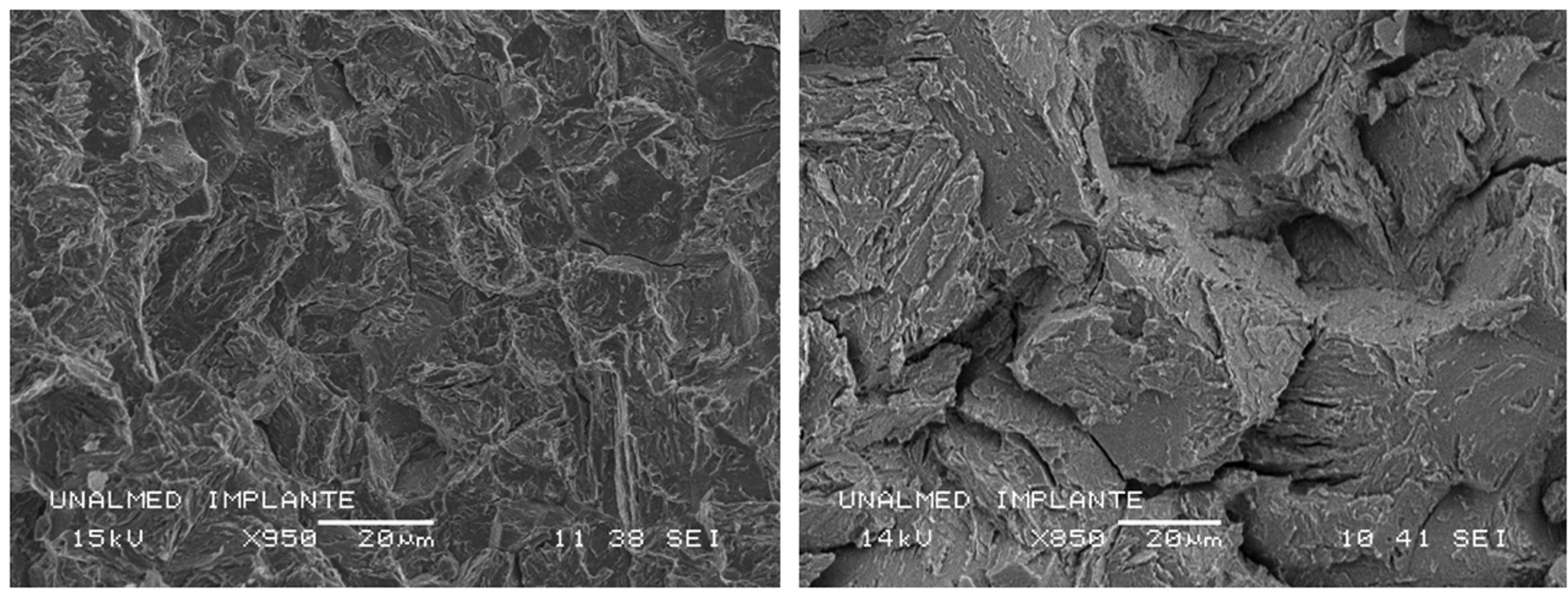

Figura 7. Imagens de microscopia eletrônica de varredura da superfície de fratura de implantes testados sob condições NH2-TP1. Imagem de Elétrons Secundários. 


\section{Conclusões}

A susceptibilidade ao desenvolvimento de fragilização induzida pelo hidrogênio (FIH) em juntas soldadas de um aço T\&R com 4,5 $\mathrm{mm}$ de espessura, utilizando consumível AWS E11018M com diâmetro de 2,4 mm e baixo aporte de calor foi avaliada por meio de um ensaio de implante modificado, utilizando planejamento experimental com o modelo ANOVA de dois fatores. A partir dos resultados obtidos deste experimento pode-se concluir o seguinte:

1. A susceptibilidade à FIH foi maior na condição que favoreceu uma maior absorção de hidrogênio pelo eletrodo (temperatura ambiente entre 25 e $31^{\circ} \mathrm{C}$ e umidade relativa entre 80 e $95 \%$ ).

2. A utilização de preaquecimento do metal de base a $75^{\circ} \mathrm{C}$, segundo as recomendações da AWS para qualquer condição de soldagem, teve baixa significância na prevenção do FIH nas condições testadas.

\section{Agradecimentos}

Os autores agradecem ao Instituto Colombiano para o Fomento das Ciências Francisco José de Caldas - COLCIENCIAS, à Universidade Nacional da Colômbia UNALMED, e COTECMAR pelo financiamento da pesquisa mediante o projeto numero 1111587816-1 RTC-512-2003 e especialmente ao Grupo de pesquisa em soldagem (Grupo de soldadura) da Universidade Nacional da Colômbia - Sede Medellín, onde foram desenvolvidos todos os testes e análises.

\section{Bibliografia}

[1] ESPEJO E. CASTRO, A. MARTINEZ, L. Mecanismos de deformación y fractura presentes en la formación de cráteres durante el impacto de proyectiles sobres chapas de acero. Ingeniería e Investigación. ISSN 0120-5609, Colombia. Vol. 48. p $12-19,2001$.

[2] ADE F. Ballistic qualification of armor steel weldments. Welding Journal, USA, V. 70, p.53-58, 1991.

[3] MADHUSUDHAN REDDY G., MOHANDAS T. Ballistic performance of high strength low-alloy steel weldments. Journal of Material Proc. Tech, Holland,, v.57, n.12, p.23-30, 1996.

[4] GIRALDO, J., UNFRIED, J. Caracterización de soldaduras de acero MIL A46100 con electrodos inoxidables. XIX Congreso de Ingeniería Naval, COPINAVAL. Guayaquil (Equador) 2005. Disponível em: <http://www.ipen.org.br/articulos2.html> Acesso em: 10 maio 2009.

[5] MOHANDAS T. MADHUSUDHAN REDDY G., B. SATISH KUMAR. Heat-affected zone softening in high strength low-alloy steels. Journal of Material Proc. Tech, Holland, v.88, n.1-3, p.284-294, 1999.

[6] GIRALDO J. E, CHAVES C. A. El agrietamiento inducido por Hidrógeno en soldaduras de acero. Revista Dyna. Colombia, v.132, p.59-64, 2001. Disponível em:

<http://www2.unalmed.edu.co/dyna2005/132/agrietamiento. html > Acesso em: 04 junho 2009.

[7] MAGUDEESWARAN, G., BALASUBRAMANIAN, V., G.
MADHUSUDHAN, R., T. S. BALASUBRAMANIAM. Effects of welding processes and consumables on tensile and impact properties of high strength quenched and tempered steel joints. J. of Iron and Steel research, international, Holland, v.15, n.6, p-87-94, 2008.

[8] MADHUSUDHAN REDDY G., MOHANDAS T., K. K. PAPUKUTTY. Effect of welding process on the ballistic performance of high strength low alloy steel weldments. Journal of Material Proc. Tech, Holland, v.74, n.1-3, 27-35, 1998.

[9] AMERICAN WELDING SOCIETY: Standard Methods for Mechanical Testing of Welds. B4.0-98. USA. 1998.

[10] MILITARY STANDARD 1941. QX117.3 Weld Procedure. Standard Code Indents. SD-X12140D. USA.. 1987

[11] CHAPEAU, W., BAUS, R. Application du soudage aux constructions No.3: Essais Mecaniques relatifs aux assemblages soudes. França.1978. 300 p. monografia.

[12] DADIAN, M. Cold cracking test methods using implants. Welding in the world, France, v.23, n.1, p.12-21, 1985.

[13] P. HART, F. WATKINSON. Development and use of the implant cracking test. USA. Welding Journal, p.349s-357s, 1972.

[14] J. UNFRIED S. Soldabilidad de un acero para blindajes usando material de aporte ferrítico de altar resistencia, 2005, 185p. Dissertação (mestrado).Facultad de minas, Universidad Nacional de Colombia, Medellin.

[15] J. UNFRIED S.,, TORRES L, E., GIRALDO, J. BASTIDAS, U. Influencia del estado de consumibles y del precalentamiento en la susceptibilidad al agrietamiento inducido por hidrógeno en la soldadura de un acero para blindajes. Rev. LatinAm. Met. Mat., Venezuela, , v.27, n.2, p.114-123, 2007. Disponível em: < http://www.scielo.org.ve/pdf/rlmm/v27n2/art06.pdf> Acesso em: 04 junho 2009

[16] AMERICAN WELDING SOCIETY. Structural Welding Code AWS D1.1. USA. 1998.

[17] MAGUDEESWARAN, G., BALASUBRAMANIAN, V., G. MADHUSUDHAN, R. Hydrogen induced cold cracking studies on armour grade high strength, quenched and tempered steel weldments. International journal of Hydrogen energy, Germany, v.33, p.1897-1908, 2008.

[18] J. UNFRIED S., GARZÓN C. M., GIRALDO, J. E. Numerical and experimental analysis of microstructure evolution during arc welding in armor plate steels. Journal of Material Proc. Tech, Holland, v.209, n.4, p.1688-1700, 2009. 